\title{
浑善达克沙地高西马格剖面孢粉分析及 植被演化的初步探讨
}

\author{
李春雨 ${ }^{1,2}$ 徐兆良 ${ }^{1 *} \quad$ 孔昭宸 ${ }^{1}$
}

(1 中国科学院植物研究所系统与进化植物学重点实验室, 北京 100093) (2 中国科学院研究生院, 北京 100039)

\begin{abstract}
摘 要 为了探讨浑善达克沙地 5000 年以来的植被演化过程, 我们对内蒙古正蓝旗境内高西马格湖人工挖掘 $2.0 \mathrm{~m}$ 深的剖面进行了较高时间分辨率的狍粉分析, 并参考狍粉组合与植被之间的对应关系, 得出: 该期的植被和 气候演化大致可以划分为 3 个阶段: 阶段 I(约 $5010 \sim 4040 \mathrm{aBP}$ ), 孢粉组合是以落叶阔叶华木 (Betula) 和蒿属 (Artemisia) 植物花粉为优势, 区域性分布有桦木林, 当时气候较今温暖偏湿。阶段 II (4 040 $1820 \mathrm{aBP}$ ), 旱生植物 花粉占优势, 其中蒿属和僽科的比值偏高, 显示了草原植被占优势; 根据该带蒿/莍（A/C) 比值的频繁变化推断该 时期可能有多次气候小波动。阶段 III (1 $820 \sim 200 \mathrm{aBP}$ ), 组合中仍然以草本植物的花粉为优势, 但僽科植物在组合 中大量增加, 推测植被应为荒漠草原, 气候更趋干旱, 接近于现代的气候状况。

关键词 浑善达克沙地 高西马格湖 狍粉分析 植被演化 全新世

\section{A PRELIMINARY INVESTIGATION ON THE HOLOCENE VEGETATION CHANGES FROM POLLEN ANALYSIS IN THE GAOXIMAGE SECTION, HUNSHANDAK SANDY LAND}

\author{
LI Chun-Yu ${ }^{1,2}$ XU Zhao-Liang ${ }^{*}$ and KONG Zhao-Chen ${ }^{1}$ \\ (1 Laboratory of Systematic and Evolutionary Botany, Institute of Botany, the Chinese Academy of Sciences, Beijing 100093, China) \\ (2 Graduate School of the Chinese Academy of Sciences, Beijing 100039, China)
}

\begin{abstract}
In order to understand the changes of palaeoclimate and palaeovegetation in Hunshandak sandy land, pollen-spores have been studied from the Gaoximage section (42 $57^{\prime} 14.2^{\prime \prime} \mathrm{N}, 115^{\circ} 22^{\prime} 3^{\prime \prime} \mathrm{E}$, Alt 1253 $\mathrm{m}$ ) in the Hunshandak sandy land, Inner Mongolia, China. Combining pollen-spore assemblages and their relationships with vegetation, the result shows that climate and vegetation have experienced three periods of changes from $5000 \mathrm{aBP}$ to present. I. From 5010 to $4040 \mathrm{aBP}$, the main pollen-spore was deciduous broadleaved plant (Betula) and the herb (Artemisia). During that time, Betula forest may have existed in that region. The climate was probably warm and humid. II. From the 4040 to $1820 \mathrm{aBP}$, the pollen assemblages of the area studied were dominated by pollen such as Artemisia and Chenopodiaceae. Grassland was developed during that time. There were probably several small climate fluctuations between aridity and humidity according to the changes of A/C (Artemisia/Chenopodiaceae) value. III. From 1820 to 200 aBP, pollen-spore assemblages show that Chenopodiaceae have dominated with some Artemisia, and the vegetation was deduced to be desert grassland. This implies that the climate became arid, which is similar to the current condition.
\end{abstract}

Key words Hunshandak sandy land, Gaoximage lake, Pollen analysis, Vegetation changes, Holocene

浑善达克沙地处于中国陆地生态系统对全球变 化响应的一级敏感区, 又是农牧交错带, 因此气候变 化及人类土地利用方式的变更对其非常敏感。该地 区广泛遗存着不同时期的古土壤、夹沙层及人类文 化遗址。这些地层记录着历史时期环境变迁及生态 系统演化的丰富信息 (施雅风, 1992)。提取这些信 息, 再结合分析人类活动历史, 对于揭示浑善达克沙
地生态系统的演化过程, 探讨浑善达克沙地的起源 和发展极为重要。

浑善达克沙地及其周边地区有关生态系统方面 的研究已取得了可喜的进展, 董玉祥等(1993)研究 了浑善达克沙地沙漠化过程, 认为该地区的沙漠化 发展过程是一个以气候为主导的自然过程; 李森等 (1995)在研究浑善达克沙地的沉积特征和环境演变 
时, 将其全新世 (10000 aBP 至今)气候变化划分为 8 个旋回, 该期间经历了升温波动期、温暖期和温干冷 干频繁波动期 3 个演变阶段; 马玉贞等(1998)对腾 格里沙漠的研究揭示了该地区晚更新世(42000 aBP 至今) 以来植被和气候演化的 5 个阶段; 任国玉等 (1997) 通过高分辨率的狍粉资料重建科尔沈沙地麦 里地区晚全新世植被变化, 并提出 $3000 \mathrm{aBP}$ 以来的 植被演化与人类活动有关, 而 $1000 \sim 660 \mathrm{aBP}$ 植物 繁盛则取决于生长季雨量的增加; 黄赐璇 (1992) 在 毛乌素沙地的研究中提出 4000 年为明显的界限, 植被由疏林草原转为以蒿、黎为主的草原, 气候转变 成干旱; 杨志荣 (1998) 的研究表明内蒙古中西部地 区全新世气候最佳期开始于 $9250 \mathrm{aBP}$ 左右, 结束于 $4000 \mathrm{aBP}$ 前后, 其中 $6850 \sim 6330 \mathrm{aBP}$ 为气候适宜 期。在中国北方的农牧交错带的形成与研究上, 李 华章(1997)根据本区沙地的形成、演化和湖泊演化 的对比, 推测近 10000 年有过 4 5 次较大的气候波 动, 自 $3000 \mathrm{aBP}$ 年以来干湿频率有加剧的趋势。

然而, 以往由于研究者所处的研究角度不同, 对 该地区及其周边环境演变的研究中常存在时间分辨 率不高、手段单一的缺陷, 且缺少居于生态系统演化 水平上的综合分析, 使其对沙地的形成与演化问题 的认识, 目前仍有较大分歧。本文通过狍粉分析, 并 参考狍粉组成与植被之间的对应关系, 初步归纳出 浑善达克沙地近 5000 年来的植被演化、气候变迁 及空间分异。这一研究不仅可以弥补我国浑善达克 这一全球变化敏感地区沙化事件研究的不足, 而且 就中国西部环境长远发展的意义而言, 结合周边地 区的研究结果, 可以探讨同一时段随经、纬向和垂向 变化所反映的植物生态的多样性。研究浑善达克地 区 5000 年以来环境变化, 不仅为该区现代植被、植 物区系形成及其未来环境变化趋势提供较为可靠的 背景资料,而且为恢复和重建该地区良好的生态环 境提供可依据的指证。

本文通过内蒙古正蓝旗高西马格湖人工挖掘剖 面样品的分析, 取得较高时间分辨率的孢粉资料, 结 合 ${ }^{14} \mathrm{C}$ 序列测年, 阐述了该地区 5000 年以来的植被 演化和环境变化的特征, 并利用重建的古植被信息 和当时气候因素的关系, 为维护该地区的植被, 改善 当地生态状况, 实现可持续性利用和发展提供了有 价值的历史资料。

\section{1 地区概况}

浑善达克沙地 (又称小腾格里沙地) 是内蒙古自
治区中东部的 4 大沙地之一, 位于华北平原的正北 方。该沙地在锡林郭勒草原的中南部, 呈东西走向, 东西长 $300 \sim 400 \mathrm{~km}$, 南北宽 $50 \sim 100 \mathrm{~km}$, 总面积约 达 $21400 \mathrm{~km}^{2}$ 。该地区年均温 $-2 \sim 2{ }^{\circ} \mathrm{C}, 7$ 月均温 $18.0 \sim 21.0{ }^{\circ} \mathrm{C}, 1$ 月均温 $-18.0 \sim-28.0{ }^{\circ} \mathrm{C}$, $\geqslant 10{ }^{\circ} \mathrm{C}$ 的年积温 $1800 \sim 2300{ }^{\circ} \mathrm{C}$, 年降水量 $250 \sim$ $400 \mathrm{~mm}$, 湿润度 $0.3 \sim 0.6$ (中国科学院宁夏综合考 察队, 1985)。

地带性土壤主要为栗钻土, 但目前所见到的基 本上是风沙土和丘间低地的沙质草甸土, 东部玄武 岩台地的阴坡有棕色森林土分布。地带性植被主要 属于温带草原, 东部具有草甸草原性质, 西部边缘属 于荒漠草原。目前的植被类型主要是风沙土上形成 的各类沙生植被。在东半部, 固定沙地主要是冰草 属 ( Agropyron)、赖草属 ( Aneurolepidium)、雀麦属 (Bromus) 等植物占优势的植物群落。在西半部, 固 定沙地主要是沙蒿 (Artemisia desertorum) 为主的沙地 半灌木群落。沙地中残留有较多的榆树 ( Ulmus pumila), 在东部, 较大沙丘的阴坡有由桦树 (Betula sp.)、柳树 (Salix spp.)、杨树 (Populus spp.) 等组成 的片林和虎榛子 (Ostryopsis) 灌丛。在中、东部较大 的沙丘阴坡一般有绣线菊属 ( Spiraea)、忍冬属 (Lonicera)、萻薇属 (Rosa) 等植物灌从, 其间常有叉 分蓼( Polygonum divaricatum) 等。

\section{2 材料和方法}

研究剖面位于内蒙古正蓝旗扎格斯台苏木政府 所在地西约 $1 \mathrm{~km}$ 、已干涸的高西马格湖岸阶地上 (425'ㅅ․ $14.2^{\prime \prime} \mathrm{N}, 115^{\circ} 22^{\prime} 3^{\prime \prime} \mathrm{E}$, 海拔 $1253 \mathrm{~m}$ )。挖掘剖 面深 $2.0 \mathrm{~m}$, 岩性自下而上依次为黄色粉砂、黑色粉 砂淤泥、黄色粉砂、深灰色黏土、灰色粉砂、灰色粉砂 质黏土和灰色粉砂。剖面选取样品进行序列 ${ }^{14} \mathrm{C}$ 测 年并进行年龄回归, 得出该剖面沉积年龄为 $5010 \sim$ $237 \mathrm{aBP}($ 图 1)。

本研究自下而上选取样品 87 份, 每份称重 $10 \mathrm{~g}$ (平均间距 $2 \mathrm{~cm}$, 时间分辨率约为 $35 \mathrm{a}$ )。采用外加 石松孢子技术 $\left(\right.$ 每个样品加入 $1 \mathrm{ml}$ 浓度为 $6.56 \times 10^{4}$ 个. $\mathrm{ml}^{-1}$ 石松孢子溶液) 的定量分析方法, 用比重为 1.90 的重液浮选提取沉积物中的孢粉, 最后用 $1: 9$ 的浓硫酸和醋酸䣶的混合液进行化石孢粉处理。在 OLYMPUS 光学显微镜 $40 \times 10$ 倍镜头下进行化石孢 粉鉴定和统计。除个别样品狍粉极少外, 每号样品 统计陆生植物孢粉 200 粒以上, 并以全部陆生植物 孢粉的总和 (陆生的乔木、灌木和草本的花粉及蒴类 
表 1 高西马格湖剖面 ${ }^{14} \mathrm{C}$ 测年表

Table $1{ }^{14} \mathrm{C}$ dating of Gaoximage section, Zhenglanqi, Inner Mongolia

\begin{tabular}{|c|c|c|c|c|}
\hline 样品号 & 岩性 & 距地表深度 & $\begin{array}{c}{ }^{14} \mathrm{C} \text { 年龄 } \\
\text { (平均值 } \pm \text { 标准误) }\end{array}$ & $\begin{array}{c}\text { 树轮校正年龄 } \\
(\text { 平均值 } \pm \text { 标准误 })\end{array}$ \\
\hline Number of samples & Lithology & Depth $(\mathrm{cm})$ & $\begin{array}{c}{ }^{14} \mathrm{C} \text { data (Means } \pm \text { standard } \\
\text { errors })(\mathrm{aBP})\end{array}$ & $\begin{array}{c}\text { Data corrected by tree rings } \\
\text { (Means } \pm \text { standard errors })(\mathrm{aBP})\end{array}$ \\
\hline 1 & 黑色粉砂淤泥 Dark silt peat & $192 \sim 197$ & $5010 \pm 90$ & $5735 \pm 135$ \\
\hline 2 & 黑色粉砂淤泥 Dark silt peat & $165 \sim 170$ & $3810 \pm 80$ & $4810 \pm 120$ \\
\hline 3 & 深灰色黏土 Dark grey clay & $108 \sim 113$ & $2850 \pm 100$ & $2950 \pm 155$ \\
\hline 4 & 粉砂 Silt & $67 \sim 72$ & $1850 \pm 80$ & $1820 \pm 120$ \\
\hline
\end{tabular}

测试单位一一国家地震局地质研究所 ${ }^{14} \mathrm{C}$ 实验室 Dating unit $-{ }^{14} \mathrm{C}$ Dating Laboratory of National Earthquake Bureau

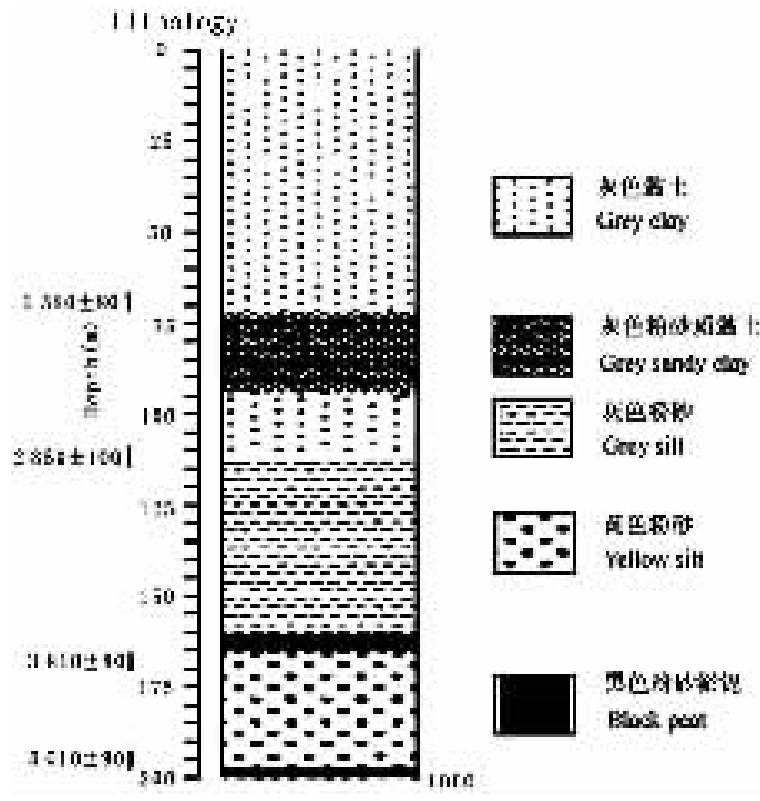

图 1 高西马格剖面岩性柱状图 Fig. 1 Lithologic column of Gaoximage section

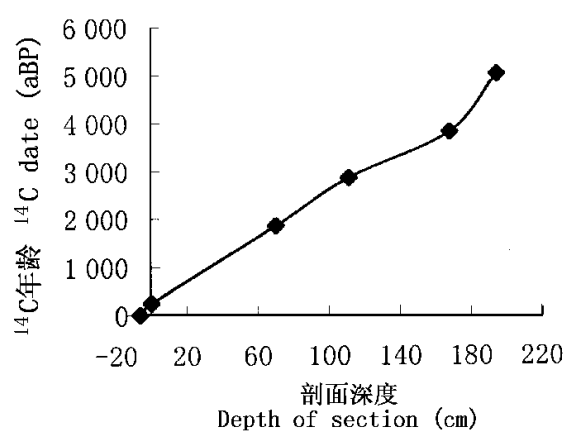

图 $2{ }^{14} \mathrm{C}$ 年龄回归

Fig. 2 The trend of ${ }^{14} \mathrm{C}$ dating

孢子)为基数计算各类植物占基数的百分比和狍粉 浓度。尽管水生的盘星藻 ( Pediastrum) 和双星藻 (Zygenma)不计入花粉基数,但也计算了它们占陆 生植物花粉总数的百分含量及浓度。计算结果用 Tilia 软件绘制出孢粉百分含量和重量浓度图 (图 3, 图 4)。

\section{3 花粉分析结果}

花粉统计表明, 该剖面优势类型植物较为单
调。共鉴定出 35 个属种, 其中乔木包括松属 ( $P i-$ nus)、桦属 (Betula)、栎属 ( Quercus)、榆属( Ulmus)、柳 属( Salix)、胡桃属 (Juglans) 和木犀科; 灌木半灌木 和草本中有蒿属 (Artemisia)、藜科、菊科、麻黄属 (Ephedra)、莎草科、禾本科、柽柳( Tamarix)、豆科、山 萝卜 (Scabiosa) 、蓄薇科、百合科、唐松草属( Thalictrum)、白刺属 ( Natraria)、石竹科、毛茛科、葎草属 ( Humulus)、丁香属 ( Syringa)、伞形花科、桑属 (Morus)、虎耳草科和地榆属 (Sanguisorba); 水生植 物中有香蒲 ( Typha)、眼子菜 ( Potamogeton)、盘星藻 和双星藻, 蕨类植物有水龙骨属 (Polypodium) 和卷柏 ( Selaginella)。

高西马格剖面花粉组合中以草本植物花粉为优 势, 其最高百分含量为 $98.8 \%$ 。草本植物花粉的主 要成分为蒿属和僽科, 二者的最高百分含量分别为 $74.4 \%$ 和 $82.2 \%$; 另外菊科、麻黄属、唐松草属也占 一定的比重, 其最高百分含量可达到 $7.2 \%$ 、 $29.9 \% 、 8.0 \%$; 乔木花粉以松最为丰富, 其次是桦, 二者最高百分含量分别为 $46.3 \%$ 和 $63.5 \%$; 水生植 物花粉很少, 最高百分含量仅为 $18 \%$, 并且以香蒲 为主。盘星藻在局部层位较丰富, 可以达到 $17 \%$; 硕类植物很少, 并且以水龙骨为主, 它的最高百分含 量为 $17.8 \%$ 。

根据剖面的孢粉组合变化, 参照有序聚类分析 和 ${ }^{14} \mathrm{C}$ 测年，高西马格孢粉组合自下而上可划分为 3 个带(注: 以下孢粉带及剖面年龄数字为回归后的年 龄): 1) 孢粉带 I( 深度为 $200 \sim 155 \mathrm{~cm}$, 约 $5010 \sim 4040$ $\mathrm{aBP})$ : 沉积物的岩性自下而上为黄色粉砂状流沙层, 黑色粉砂淤泥, 黄色粉砂。孢粉组合是以落叶阔叶的 桦木和蒿属植物花粉为优势, 它们的百分含量分别为 $16.7 \% \sim 63.5 \%$ 和 $21.3 \% \sim 47.6 \%$, 浓度分别为 31.1 $\sim 132$ 粒 $\cdot \mathrm{g}^{-1}$ 和 $13 \sim 233$ 粒 $\cdot \mathrm{g}^{-1}$; 其它乔木植物还有松 $\left(2 \% \sim 43 \%, 9.9 \sim 39.9\right.$ 粒 $\left.\cdot \mathrm{g}^{-1}\right)$; 草本和灌木植物有 藜科 $\left(2 \% \sim 16 \%, 5.6 \sim 23.1\right.$ 粒 $\left.\cdot \mathrm{g}^{-1}\right)$, 麻黄 ( $1 \% \sim$ $16 \%, 5.4 \sim 19.8$ 粒 $\left.\cdot \mathrm{g}^{-1}\right)$ 。其它种类植物花粉少见。 


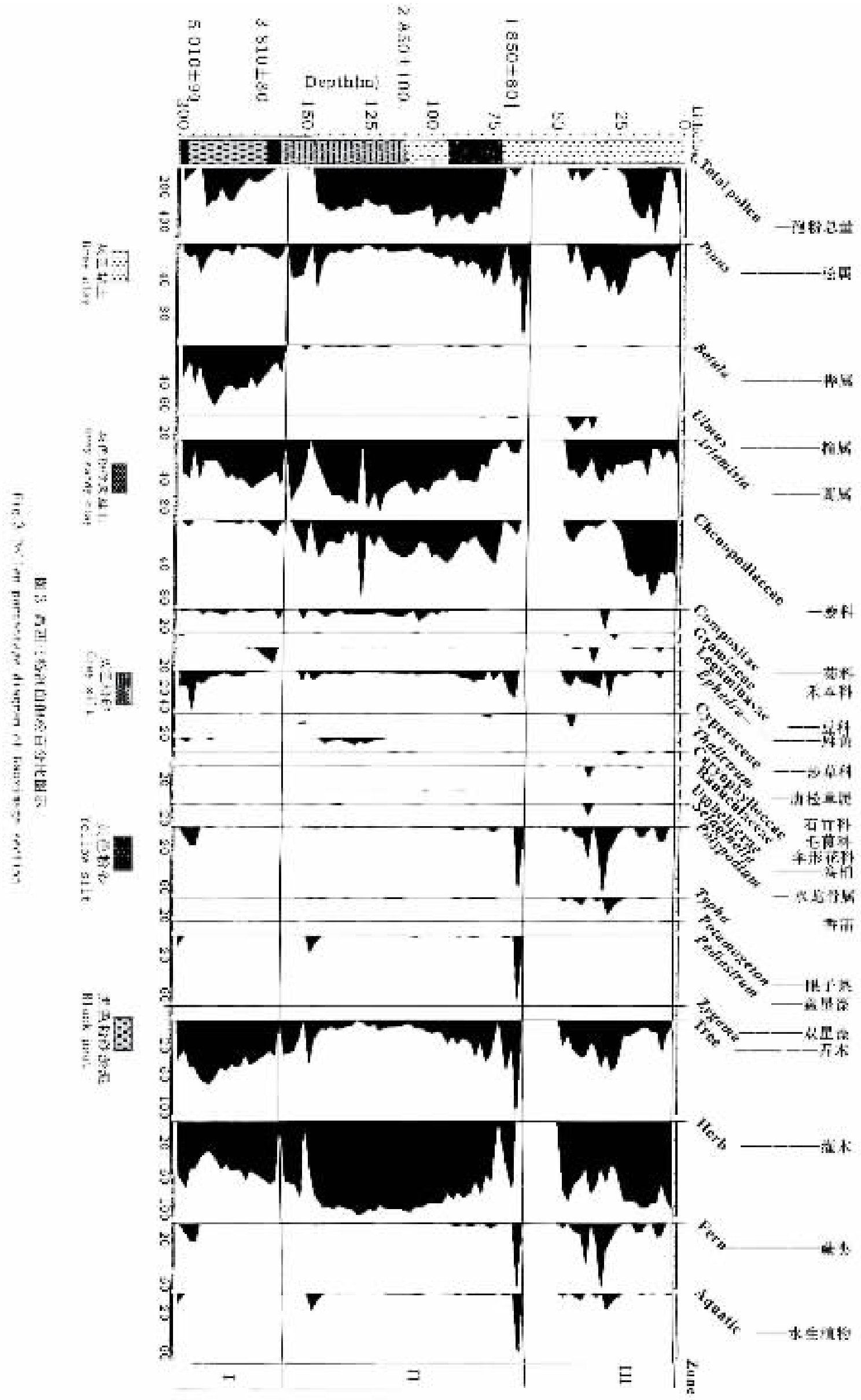




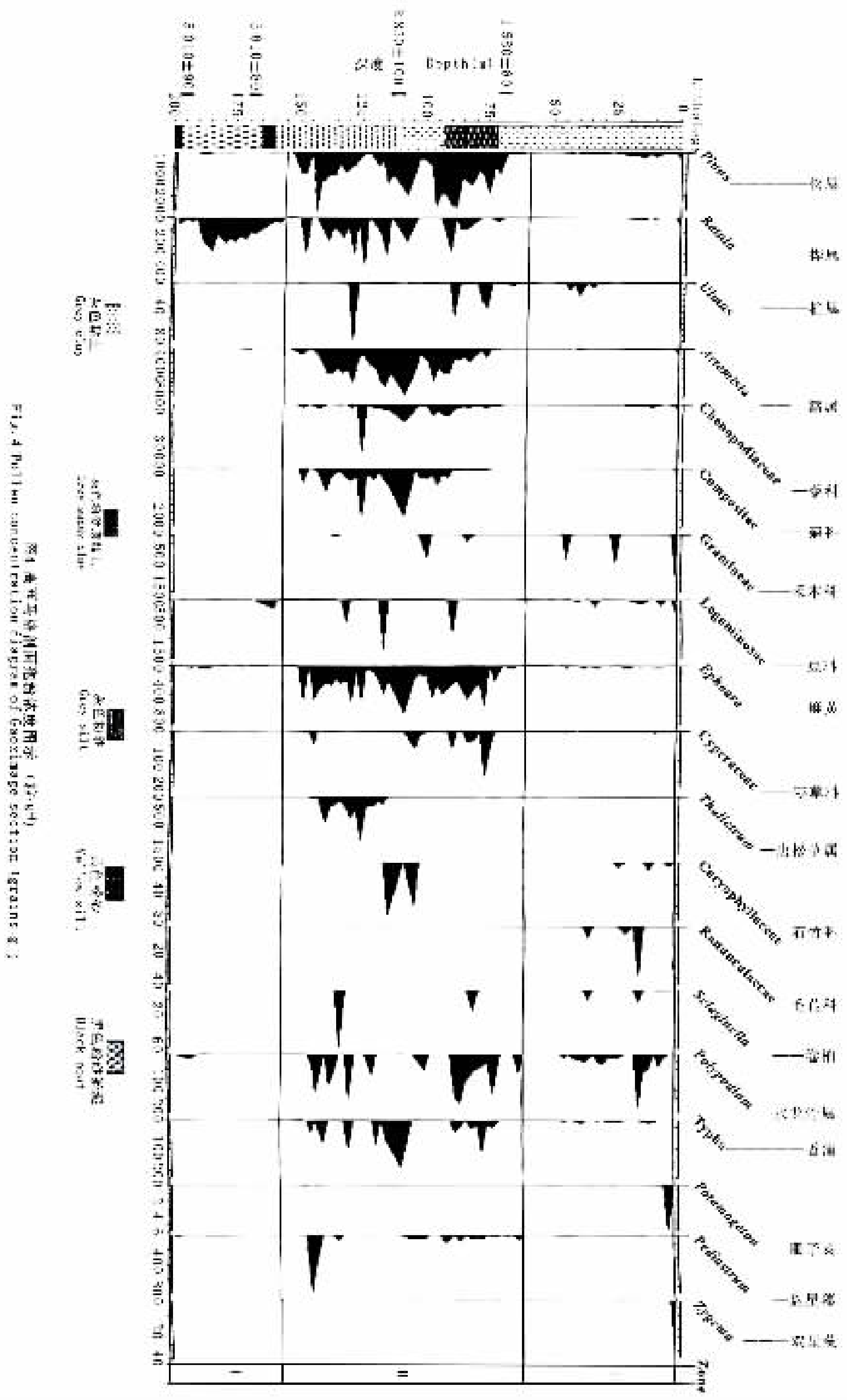


2) 孢粉带 II (深度为 $155 \sim 59 \mathrm{~cm}, 4040 \sim 1820 \mathrm{aBP}$ ), 岩性下部为灰色黏土, 上部为灰色粉砂。本带的花 粉浓度明显增高, 植物多样性增加, 草本旱生植物花 粉为优势, 主要有蒿属 (9\% 74\%, 23.1 9 534.6 粒 $\left.\cdot \mathrm{g}^{-1}\right)$ 和藜科 $\left(7 \% \sim 80 \%, 11.5 \sim 23767\right.$ 粒 $\left.\cdot \mathrm{g}^{-1}\right)$ 。 计算得出 $\mathrm{A} / \mathrm{C}$ 值的波动范围为 $0.05 \sim 6.23$ 。菊科 $\left(0.7 \% \sim 5.9 \%, 21.1 \sim 1630\right.$ 粒 $\left.\cdot \mathrm{g}^{-1}\right)$ 也占一定比 例, 麻黄属 (1.6\% 11\%,37.6 652 粒 $\cdot \mathrm{g}^{-1}$ ) 和唐松 草 $\left(1.3 \% \sim 8.0 \%, 263.8 \sim 1124\right.$ 粒・ $\left.\mathrm{g}^{-1}\right)$ 在此带出 现。乔木中松属 ( $8 \% \sim 42.6 \%, 72.4 \sim 1863$ 粒・ $\left.\mathrm{g}^{-1}\right)$ 经历了一个阶段性降低并且回升, 在 $4040 \sim$ $3350 \mathrm{aBP}$ 期间, 其花粉百分含量降低( 19\% 1\%) 花粉浓度偏低 $\left(205 \sim 798\right.$ 粒 $\left.\cdot \mathrm{g}^{-1}\right)$, 在 $3350 \sim 1820$ $\mathrm{aBP}$ 期间, 其百分含量升高( $3 \% \sim 42 \%$ ), 花粉浓度 上升 $\left(81.1 \sim 1863\right.$ 粒 $\left.\cdot \mathrm{g}^{-1}\right)$ 。3) 孢粉带 III( 深度为 59 $\sim 0 \mathrm{~cm}, 1820 \sim 200 \mathrm{aBP})$, 由 ${ }^{14} \mathrm{C}$ 年龄回归分析得出 此层位表土并非现代沉积, 上部为 $200 \mathrm{aBP}$ 左右剥 蚀层。本带主要以草本植物花粉占优势, 其中藜科 花粉的百分含量要大于蒿属。越接近地表, 松属 (53\% 5\%)、蒿属( $45 \% \sim 9 \%)$ 的百分含量越低, 藜 科的百分含量越高 $(40 \% \sim 80 \%)$ 。与此同时, 水龙 骨百分含量降低( $27 \% \sim 2 \%)$, 香蒲的百分含量下降 (18\% 0.5\%)。此带的花粉浓度不高, 具体如下: 松属 $\left(18.6 \sim 246\right.$ 粒・ $\mathrm{g}^{-1}$ )、蒿属 (22.6 1356 粒・ $\left.\mathrm{g}^{-1}\right)$ 和藜科 $\left(6.4 \sim 2835\right.$ 粒 $\left.\cdot \mathrm{g}^{-1}\right)$ 、麻黄 $(4 \sim 398$ 粒・ $\left.\mathrm{g}^{-1}\right)$ 。由此推测这段时期植被覆盖率偏低。

\section{4 古植被恢复}

高西马格剖面的孢粉资料揭示了浑善达克沙地 中部 5000 年来的植被演替状况。其特征如下:

1） $5000 \sim 4000 \mathrm{aBP}$ 期间,花粉组合主要以桦 木和蒿属植物花粉为主导。尽管当时花粉浓度低, 孢粉贫乏, 但是乔木的桦树和草本的蒿属占了很大 一部分比例, 推断是一个以桦木和蒿属占主成分的 草原或疏林草原。因为桦木花粉的含量在 $30 \%$ 以 上, 就可以断定桦林就地存在或者短距离内存在 ( Liu et al., 1999)。当时气候为温暖偏湿。

2) $4000 \sim 2000 \mathrm{aBP}$ 期间, 孢粉组合中旱生植 物花粉为优势, 不仅花粉浓度高, 而且植物多样性增 高, 推测为草甸草原。草本植物花粉的百分含量远 远大于乔木植物花粉百分含量; 在草本植物花粉中, 蒿属的百分含量总体上大于愁科的百分含量, 并且 随着地层的变化而有起伏波动; 从总的时间尺度来 看, 随着地层年龄越新, 蒿属的百分含量越低, 藜科
的百分含量越高。同时, 根据此期间变化的 $\mathrm{A} / \mathrm{C}$ 比 值推测该时期内可能有多次目前难以断定的干湿气 候的波动。具体事件待狍粉的加密分析后方可得 出。

3) $2000 \sim 200 \mathrm{aBP}$ 期间, 孢粉组合仍然以草本 植物的花粉为优势, 但花粉的浓度偏低。随着僽科 植物在孢粉组合中的大量增加, 蒿属百分含量变少, 烣类和水生植物花粉的百分含量降低, 麻黄百分含 量增加, 推测植被应为荒漠草原, 气候变得更加干 旱, 接近于现代的气候状况。

\section{5 结果和讨论}

从浑善达克沙地及其邻近地区以往的研究结果 来看, 李森等(1995) 将浑善达克沙地全新世(10000 $\mathrm{aBP}$ 至今)气候演化划分为 8 个旋回, 经历了升温波 动期、温暖期和温干冷干频繁波动期 3 个演变阶段; 董玉祥等(1993)认为该地区 5000 年来经历了退缩、 活化的沙漠化的正、逆过程, 逆过程发生在 5000 $4000 \mathrm{aBP}$ 。在这几次正逆反应过程中, 沙漠化是受 制于气候变化的自然过程; 本研究的 3 个孢粉带的 孢粉资料显示出来的浑善达克沙地中部 5000 年以 来的植被演化状况 (疏林草原一草甸草原一荒漠草 原)和气候变化的结果, 与前人认为 $5000 \sim 4000$ $\mathrm{aBP}$ 属于较稳定的温暖期的研究相类似, 并符合中 国北方全新世的植被演化和气候变化的总体趋势。

孢粉分析结果表明, 从 $2000 \mathrm{aBP}$ 到今, 代表干 旱荒漠草原气候的藜科植物花粉的增多, 代表湿润 草原的蒿属植物花粉减少, 同时总体花粉浓度降低, 而且该期间孢粉组合中没有出现与人类影响活动有 关的孢粉类型, 所以初步推断导致浑善达克沙地的 环境变化主要为自然原因。

$4000 \sim 2000 \mathrm{aBP}$ 期间, 由 $\mathrm{A} / \mathrm{C}$ 比值的波动可以 看出, 该地区存在着几次小规模的湿润和干旱的气 候波动。为了取得更好的分析结果, 应进一步选择 该剖面中孢粉保存好的层位进行加密分析, 更好地 恢复当时植被及弄清气候波动状况, 探讨本研究区 域的植被演化状况。

在剖面中 $45 \sim 59 \mathrm{~cm}(2000 \sim 1460 \mathrm{aBP}$ ) 的孢粉 样品中出现了花粉总数急剧下降的现象, 所以从孢 粉百分图谱上来看, 该时期内出现一个巨大的花粉 百分含量峰值。那么这种变化是由于气候事件还是 其它原因造成, 有待于进一步研究与探讨。

本研究也存在着一些不足, 通过单一的孢粉的 分析不一定准确地恢复当时的古植被, 而且在此历 
史期间, 人为影响究竟占多大比例, 因缺少足够的考 古学记录, 尚不得而知。我们将会在以后的研究中 更进一步探讨这些问题。

\section{参 考 文 献}

Dong, Y. X. (董玉祥) \& Y. H. Liu (刘毅华). 1993. Study on the sandy desertification process of Hunshandake sandy land in recent 5000 years. Arid Land Geology (干旱区地理), 16 (2) : $45 \sim 51$. (in Chinese with English abstract)

Huang, C. X. (黄赐璇) . 1991. The change of the physical environment of southern Maowushu sandy land during Holocene. Geographical Research (地理研究), 10(2) : 52 59. (in Chinese with English abstract)

Li, H. Z. (李华章). 1991. On characteristics of Holocene environmental vicissitudes of agro-animal husbandry transitional zone in north China. Journal of Beijing Normal University (Natural Science Edition) (北京师范大学学报 (自然科学版)), 27: 103 109. (in Chinese with English abstract)

Li, S. (李森), W. Sun (孙武), X. Z. Li (李孝泽) \& B. Zhang (张勃). 1995. Sendimentary characteristics and environmental evolution of Otindag sandy land in Holocene. Journal of Desert Research(中国沙漠) , 15: 323 331. (in Chinese with
English abstract)

Liu, H. Y., H. T. Cui, R. Pott \& M. Speier. 1999. Surface pollen of the woodland-steppe ecotone in the southeastern Inner Mongolia, China. Review of Palaeobotany and Palynology, 105: $237 \sim 250$.

Ma, Y. Z. (马玉贞), H. C. Zhang (张虎才) \& J. J. Li (李 吉均). 1998. On the evolution of the palynoflora and climatic environment during late Pleistocence in Tengger desert, China. Acta Botanica Sinica(植物学报), 40: $871 \sim 879$. (in Chinese with English abstract)

Ren, G. Y. (任国玉) \& L. S. Zhang (张兰生). 1997. Late Holocene vegetation in Maili region, Northeast China, as ingerred from a high-resolution pollen record. Acta Botanica Sinica(植物 学报), 39: $353 \sim 362$. (in Chinese with English abstract)

Shi, Y. F. (施雅风). 1992. The climates and environments of Holocene Megathermal in China. Beijing: China Ocean Press. $161 \sim 167$. (in Chinese)

The comprehensive scientific expedition to Ningxia, CAS (中国科 学院宁夏综合考察队). 1985. Flora of Inner Mongolia. Beijing: Science Press. $787 \sim 833$. (in Chinese)

Yang, Z. R. (杨志荣). 1998. The preliminary study on the climate and environment during the Megathermal of the Holocene in the middle-west Inner Mongolia. Scientia Geographica Sinica (地 理科学), 18: 479 485. (in Chinese with English abstract)

责任编委: 倪 健 责任编辑: 姜联合

\section{欢迎订购《中国生态学》}

《中国生态学》是作者所创立的新学科, 是继“中医”之后具有独立地位、有中国特色的自然科学体系。其 学术创新在于建立有中国特色的生态学理论体系。全书分为三篇, 第一篇介绍了中国生态学的概念和理论; 第二篇为中国生态学的应用与发展; 第三篇回顾总结了中国古代的生态学理论和实践。作者详细论述了“中 国生态学”的基本概念和基本理论, 概述了“中国生态学”的模型系统, 探讨了中国传统文化的生态学原理以 及中国古代生态学思想对现代科学、文化等各个方面的深刻影响。特别是对于儒家和道家的生态学思想、中 国的古代的山水诗词和山水画的科学价值、“风水理论”的生态学依据、中国古代园林的设计理论以及建筑思 想都有独到的见解, 并用 “中国生态学” 的概念和理论对现代生态学的有关问题进行了阐释。最后, 作者提出 了生态学的统一理论和生命科学的大统一理论。

本书可供从事生态学、生命科学、环境科学、科学史、文化史、中国传统文化, 包括传统哲学、美学、文学、 医学、易学、经学等领域的研究人员参考, 也可用作大学相关专业学生和研究生的学习参考书。

邮购汇款地址: 兰州市天水路 298 号兰州大学生命科学学院甘肃省植物学会( 邮政编码: 730000)

联系人: 徐世健, 刘艳红

电话: 0931 - 4967180 传真: $0931-4967178$

E-mail: liuyh@gsstc.gov.cn; xutxzyhm@163.com 手机:13038769251;13919170189 